\title{
USO DO MÉTODO MULTICRITÉRIO ELECTRE TRI PARA CLASSIFICAÇÃO DE ESTOQUES NA CONSTRUÇÃO CIVIL
}

\author{
Nadia Kelner Szajubok \\ Caroline Maria de Miranda Mota \\ Adiel Teixeira de Almeida * \\ Universidade Federal de Pernambuco (UFPE) \\ Recife - PE \\ gpsid@ufpe.br \\ carolmm@,ufpe.br \\ aalmeida@ufpe.br \\ * Corresponding author / autor para quem as correspondências devem ser encaminhadas \\ Recebido em 11/2005; aceito em 08/2006 após 1 revisão \\ Received November 2005; accepted August 2006 after one revision
}

\begin{abstract}
Resumo
O setor da construção civil ocupa um lugar de destaque para o desenvolvimento econômico e social do país, gerando bens direcionados às necessidades humanas. O processo de gestão de materiais tem assumido grande relevância, apontando seu caráter estratégico de potencial redutor de custos e propulsor da inovação tecnológica e organizacional das empresas de construção. A questão básica a ser tratada é a forma como pode ser realizada uma classificação dos materiais à luz de múltiplos critérios, visto que esse procedimento não é aplicado no setor, e que pode ocasionar problemas como falta de materiais e interrupção da produção. Portanto, este trabalho apresenta o uso de um modelo de decisão multicritério, para o processo de gestão de materiais na construção civil, visando classificar os materiais de uma obra em três categorias às quais devem ser adotados procedimentos de políticas de estoques.
\end{abstract}

Palavras-chave: decisão multicritério; ELECTRE TRI; construção civil; estoques.

\begin{abstract}
The civil construction sector has an important place in the country's economic and social development, producing goods of attendance related to the human necessities or to the productive capacity. The management material process has assumed great relevance due to its strategic role on reducing costs and pushing up the construction companies' technological and organizational innovation. The basic question to be considered is the way that material classification can be done using multiple criteria; hence this procedure is not being use in the construction site and may lead into problems such as lack of materials and production interruption. Thus, this work presents a case study, aiming to present a structuralized multicriteria model to the decision process in the civil construction materials management. The model aim to categorize the material in three classes.
\end{abstract}

Keywords: multicriteria decision; ELECTRE TRI; civil construction; inventory. 


\section{Introdução}

A construção civil ocupa, na engenharia, lugar de destaque à medida que desenvolve, continuamente, atividades econômicas que beneficiam a sociedade como um todo e, por via de conseqüência, objetiva a melhoria da qualidade de vida do homem moderno. O setor coopera para o desenvolvimento econômico e social do país, gerando bens de atendimento direcionados às necessidades humanas ou que fazem parte da capacidade produtiva.

Em razão da escassez de habitações em nível nacional, o subsetor de edificações da construção civil jamais deixou de vender o que estava sendo produzido. Tal circunstância eliminou o fator competitivo que provocou a ineficiência, o desperdício e a improvisação, fatores esses determinantes de maiores custos.

Tendo seus lucros assegurados de forma permanente, os empresários não dispensaram o devido apreço ao gerenciamento da cadeia de suprimentos no ambiente produtivo. Porém, com o transcorrer do século XX, a situação econômica brasileira foi sendo, aos poucos, levada a uma integração universal, decorrente da globalização. Conseqüentemente, novas tecnologias foram sendo absorvidas e uma nova dinâmica passou a ser adotada, de forma incipiente, no processo produtivo de construção civil. Hoje, o gerenciamento da cadeia de suprimentos adquiriu o respeito que lhe cabe ter na cadeia produtiva.

O suprimento é a fase da aquisição, fabricação, transporte e entrega, na obra, de todos os equipamentos, estruturas e materiais em geral necessários à construção e indispensáveis à execução do empreendimento. A responsabilidade quanto ao suprimento, no seu conceito mais amplo e atual, não se restringe apenas a materiais e produtos, mas também abrange os serviços e a mão-de-obra. Benefícios inquestionáveis são produzidos com o gerenciamento da cadeia de suprimentos, mais especificamente, no processo de administrar o estoque.

Na busca de oferecer uma contribuição robusta e valiosa ao construtor, centra-se o trabalho, ora desenvolvido, na confecção de um modelo multicritério de apoio a decisão que possa ser adaptado para a obtenção de um bom controle dos estoques e benefícios resultantes.

Esse modelo deve incorporar as dificuldades por parte do gerente de obras em usar metodologias de apoio a decisão mais sofisticadas. Esses métodos, em geral, requerem a determinação de diversos parâmetros de difícil interpretação física.

\subsection{Relevância do estudo}

A administração de materiais na construção civil, especialmente nas maiores obras, é uma função importante e complexa para a obtenção de uma melhora substancial no projeto. Sua importância reside no fato de ela ter substancial importância no custo e tempo do projeto. Técnicos estimam e análises históricas indicam que os materiais representam de $50-60 \%$ do custo do projeto (CII, 1988; Limmer, 1997) e controlam 80\% do cronograma (Kerridge, 1987 apud Homaid, 2002). A falta de itens, quando necessários à obra, é identificada como a maior e mais comum e freqüente causa de atrasos em obras (CII, 1988), e um sistema integrado de administração de materiais aumenta de $10-12 \%$ a produtividade (Bell \& Stukhart, 1987).

Um estudo de Homaid (2002) destacou que na construção civil, o planejamento dos materiais e das atividades da obra não são integrados e a maioria das requisições é feita externamente, não tendo uma dependência para com a seqüência de operações. Essa falta de integração dificulta o gerenciamento de materiais na obra. O estudo de Marsh (1985), por sua vez, 
indica que, enquanto a indústria de manufatura gasta $1 \%$ dos seus custos em administração do sistema de suprimentos, a indústria de construção gasta apenas $0,15 \%$.

$\mathrm{O}$ processo de fornecer materiais às obras é razoavelmente complexo para um projeto de construção. $\mathrm{O}$ processo envolve muitas etapas, realizadas em diversos departamentos diferentes, tais como o projeto, a compra, a produção e a contabilidade. O número de materiais é enorme e há uma grande variedade de fornecedores, desde as pequenas empresas com baixa tecnologia às modernas indústrias de capital intensivo.

Gerenciar esse estoque de materiais com a mesma atenção pode ser dispendioso, fazendo com que se encontre uma forma de dar atenção diferenciada a certos itens, adotando critérios que permitam distinguir claramente a importância do insumo segundo esses critérios.

Assim, é importante analisar o problema de estoques em construção civil, considerando-se os critérios qualitativos e quantitativos para a confecção de um modelo de curva $\mathrm{ABC}$, aplicado ao setor da construção civil, utilizando métodos multicritério de apoio a decisão.

Os estudos do CII (Construction Industry Institute), em 1985 e 1986, enfatizaram o valor prático de uma administração de materiais apropriada. Esses estudos mostraram que reais economias existem na melhora da produtividade do trabalho, na redução do excesso de materiais e no aumento do fluxo de caixa.

\subsection{Problemas da engenharia e da indústria da construção}

A indústria da engenharia e construção oferece desafios formidáveis, porém continua com a performance insatisfatória. Sofre com margens de lucro baixas e projetos com problemas de programação e orçamento. Um exame britânico da indústria de construção mostrou que a margem de lucro no trabalho de construção é de 1 à $2 \%$ (Agapiou, 1998). O Instituto Americano da Indústria de Construção (CII) (1988) mostra que aproximadamente 1/3 dos projetos falham em custo e programação. Um aspecto crítico da falha de projeto é o atraso da construção, que resulta freqüentemente em reclamações. Um outro exame no Reino Unido mostra que $52 \%$ dos projetos de construção terminam com reclamação de algum tipo (Conlin, 1997).

A indústria de construção recebe muitas críticas. Mohamed (1996) salienta que as práticas e os mecanismos da indústria de construção são ineficientes e conduzem a inevitáveis desperdícios. O estudo de Lim (1995) sobre a produtividade da construção em Singapura mostra que a indústria é percebida como um setor da baixa produtividade.

Uma investigação no desperdício do tempo revela que a mão-de-obra da construção gasta uma quantidade considerável de tempo esperando o material chegar à obra. A quantidade de trabalho em atividades sem agregação de valor foi de $40 \%$ da duração total da obra, desde a concepção à conclusão (Mohamed, 1996).

O CII (1988) nos Estados Unidos, em sua vasta investigação na indústria da construção, concluiu que o desempenho do projeto, medido nos termos de custo, programação, técnica, qualidade, segurança e objetivos do lucro, tem uma substancial capacidade de melhoria para a indústria como um todo. O Conselho da Indústria de Construção (CIB) do Reino Unido sugeriu especificamente que a indústria de construção deve ser mais competitiva e visa reduzir custos de construção em 30\% (Garnett, 2000). Mohamed (1996) calcula que a economia de tempo de $25 \%$ é realizável em uma atividade de construção sem aumento de recursos. 


\section{Gestão de Estoques na Construção Civil}

São várias as definições de estoque. Neste trabalho, entende-se por estoque qualquer quantidade de bens físicos que sejam conservados, de forma improdutiva, por algum intervalo de tempo (Moreira, 1998). Constituem estoque tanto os produtos acabados que aguardam venda ou despacho, como matérias-primas e componentes que aguardam utilização na produção. Na construção civil, são feitos estoques de materiais para a construção; logo, estoque de entrada.

Manter estoques significa imobilizar recursos e incorrer em uma série de custos, alguns facilmente identificáveis e calculáveis e outros de difícil mensuração, mas que nem por isso deixam de existir.

Na construção civil, o principal objetivo em manter estoques é compensar as incertezas entre fornecimento e demanda, pois existe um tempo entre o pedido ser feito e o produto chegar à obra, e nesse intervalo é necessário ter a matéria-prima para que não haja uma interrupção no processo construtivo. Portanto, esse tipo de estoque será o principal objetivo deste estudo.

A construção civil não se caracteriza por manter estoques a longo prazo, uma vez que se apóia na produção "puxada", em que os insumos para a execução das tarefas chegam à obra de acordo com o serviço a ser realizado. Entretanto, existe limitação quanto ao volume de material a ser entregue no canteiro de obras, devido à capacidade do veículo que realiza o transporte e às flutuações nos preços dos materiais. Portanto, ocorre a aquisição de insumos em quantidade maior do que seria utilizada em determinada atividade e o reembolso financeiro previsto para essa. Desse modo, devem ser implementadas pequenas alterações em relação à programação dos serviços executados para que haja melhor utilização desses insumos.

Os insumos na construção civil possuem uma demanda dependente do planejamento realizado previamente. Segundo Leite \& Possamai (2001), o planejamento da programação de obras em engenharia implica, inicialmente, uma previsão das atividades a serem realizadas, dos recursos necessários, dos custos estimados, dos prazos e de tantos outros elementos importantes para a execução e para o acompanhamento da obra.

\subsection{Métodos usados para a classificação dos estoques}

O controle de inventário tem sido alvo de muitos estudos relatados na literatura. Como resultado, uma larga coleção de conceitos e técnicas estão disponíveis para o controle de estoques, como os modelos estocásticos para a determinação da quantidade de pedido, técnicas de projeção de demanda e técnicas $\mathrm{ABC}$. Recentemente, os sistemas de administração MRP (Manufacturing Resource Planning) e ERP (Enterprise Resource Planning) foram adicionados.

Essas abordagens para o controle de inventário têm provocado um grande valor na determinação de parâmetros de estoque e planejamento de recursos, tendo sido seus valores questionados com respeito a problemas práticos de controle de inventário. Adicionalmente, vários autores afirmam que muitos métodos quantitativos existentes na administração de produção e pesquisa operacional são insuficientes para enfrentar a complexidade das organizações (Hayes, 1998; Lovejoy, 1998; Machuca, 1998). Esses autores oferecem um amplo escopo na administração de produções, incluindo aspectos qualitativos e link com outras áreas da organização. 


\subsubsection{Curva ABC}

Na construção civil, devido à grande variedade de itens em estoques a serem controlados, as empresas utilizam a classificação ABC 20-80, baseada na lei de Pareto (1946) como um guia para a priorização dos itens em estoque a serem gerenciados com maior atenção. Tipicamente, a curva $\mathrm{ABC}$ mostra que $20 \%$ dos artigos respondem por $80 \%$ ou mais do valor do consumo, e daí deriva a regra 20-80. Entretanto, não há nenhuma convenção fixa a respeito do que constitui a categoria $\mathrm{A}, \mathrm{B}$ ou $\mathrm{C}$. A escolha de classificar limites pode ser determinada de acordo com o percentual dos itens ou baseada nos percentuais cumulativos do valor de consumo; conseqüentemente, é arbitrária e é baseada na natureza do negócio, no julgamento e experiência do analista e na causa das ações que podem ser tomadas.

Apesar do largo uso, existem alguns problemas associados com a análise $\mathrm{ABC}$. Os principais são:

- Como selecionar um bom critério de medida;

- Qual o número de categorias mais apropriado;

- Como classificar os itens nas classes.

Cabe salientar que uma análise exclusiva $\mathrm{ABC}$ pode levar a distorções perigosas para a empresa, pois ela não considera a importância do item em relação ao sistema como um todo.

Para itens de inventário, o critério geralmente é o preço unitário do item multiplicado pela quantidade (custo total do uso). Entretanto, para muitos itens, esse critério pode tornar-se inadequado. $\mathrm{O}$ problema em usar esse critério para ranquear os itens do estoque é enfatizar itens que possuem o custo total do uso alto, mas que não são importantes para a operação da produção, o serviço da empresa, e não enfatizar itens que possuem o custo total do uso baixo, mas que são importantes. Logo, classificando o inventário da empresa dessa forma pode-se induzir a um mau gerenciamento dos componentes do estoque.

\subsubsection{Métodos de apoio a decisão}

Os principais problemas no uso da Curva $\mathrm{ABC}$ sugerem considerar um conjunto de critérios para proceder a classificação de itens em estoque. O número de critérios usados para a administração de estoque e a importância relativa entre os critérios pode ser variado, dependendo da natureza e do tipo de empresa.

Quando mais de um critério for utilizado, as empresas têm de enfrentar um novo problema de como classificar, analisar e ordenar os itens do inventário. Depois disso, os itens podem ser agrupados (como na classificação $\mathrm{ABC}$ ) para melhor refletir os objetivos da administração de estoques.

Cohen \& Ernst (1988) sugerem uma classificação multicritério e algumas políticas de controle de estoque. Esses autores descrevem uma abordagem de usar agrupamentos (clustering) como uma maneira de combinar grupos de itens e afirmam que esse método provê uma melhora do método típico $\mathrm{ABC}$. A principal vantagem é que ela pode acomodar um grande número de combinações de atributos, entretanto, requer dados substanciais para o uso da análise de fator (procedimento de clustering), o qual pode ser impraticável nos típicos ambientes de estoques. Além disso, os agrupamentos (clusters) devem ser reavaliados a fim classificar itens novos do estoque.

Flores \& Whybark $(1986,1987)$ usaram a análise multicritério $\mathrm{ABC}$ e descreveram vantagens, como a redução de investimento e lead time (tempo de ressuprimento). Eles não 
propuseram um método específico para integrar a utilização de vários critérios e apenas sugeriram uma forma de reduzir a classificação num grupo ABC. Os critérios considerados foram: certeza de suprimento, taxa de obsolescência, avaliabilidade, substitutabilidade, lead time e impacto da falta do item.

Flores et al. (1992) estenderam os resultados propostos por Flores \& Whybark $(1986,1987)$ e usaram o método AHP (Analytical Hierarchy Process) para integrar e usar vários critérios para ordenar os itens do estoque. Os critérios utilizados foram: criticidade, lead time, custo total de uso e preço unitário. Os dois últimos foram usados como critérios distintos. O problema dessa abordagem é que os itens são usualmente medidos em unidades diferentes, por exemplo, o preço unitário de um item é dado por $\$ / \mathrm{Kg}$, enquanto o de outro é em $\$ /$ metro, e para a utilização desse método a unidade de um critério não deve mudar de item para item. Guvenir \& Erel (1998) corrigiram esse problema e aplicaram o AHP para a classificação de estoques com múltiplos critérios, unindo os critérios de custo total de uso e preço unitário num único critério que é custo total de uso, o qual tem a unidade em dólar. Esses autores também usaram algoritmos genéricos para dar pesos aos critérios, e o método proposto foi denominado GAMIC (Genetic Algorithm for Multicriteria Inventory Classification). O GAMIC foi comparado com o AHP, chegando-se à conclusão de que a classificação feita pelo GAMIC foi mais próxima da classificação feita pelo decisor do que a obtida pelo AHP.

O método AHP para a classificação ABC também foi utilizado por Gajpal et al. (1994), Partovi \& Burton (1993) e Partovi \& Hopton (1994). O método AHP, apesar de muito utilizado, não é bem conceituado devido às inconsistências que ele apresenta (Tung \& Tang, 1998; Barzilai \& Golany, 1994).

Gomes (1996) apresenta um estudo de classificação de estoques utilizando a análise ABC multicritério, que faz uso da teoria dos conjuntos aproximativos - TCA, destacando os fundamentos da metodologia e exemplos de aplicação. De acordo com Gomes \& Gomes (1999), a TCA é caracterizada por um conjunto de elementos que não pode ser precisamente definido em relação aos seus atributos, sendo baseada na relação de indiscernibilidade entre dois objetos. A aplicação da TCA no controle de estoques também é relevante para tratar os casos em que o decisor tem dúvidas quanto à importância entre os fatores considerados na análise.

Em um estudo sobre classificação de estoques Lenard \& Roy (1995) propuseram construir famílias de artigos, em que a família é um conjunto de artigos nos quais as decisões devem ser as mesmas em termos de dois critérios: número de faltas por ano e período de reposição. A decisão de estoque é tomada após a construção das famílias, baseada num modelo multicritério que utiliza uma aproximação de curvas eficiente. A determinação dessa curva não é um processo fácil, e para cada critério é formada uma curva, não mais existindo uma política ótima, mas um conjunto eficiente de políticas no qual os trade offs podem ser visualizados pelos critérios, e o decisor pode tomar a melhor solução. Esse modelo, entretanto, é de difícil aplicação no contexto da construção civil brasileira, pois requer um alto investimento de tempo na análise.

\section{Métodos Multicritério de Apoio a Decisão}

O escopo deste trabalho é apresentar o uso de modelagem multicritério no processo de classificação de estoques na indústria da construção civil. Os modelos multicritério de apoio a decisão têm sido aplicados a uma grande quantidade de problemas de planejamento de produção, tais como: planejamento agregado da produção, balanceamento da linha de 
montagem (Malakooti, 1989; Yang et al., 1988), problemas de layout, produtos e planejamento de processo (Agrell, 1994; Yoshimura et al., 1989) e controle de inventário. Esta área do conhecimento possui um amplo conjunto de ferramentas cujo objetivo é auxiliar um indivíduo ou grupo de pessoas (decisor) no desenvolvimento de um processo de decisão.

Quando modelamos um problema de decisão multicritério, várias problemáticas podem ser consideradas. Roy (1996) distinguiu quatro problemáticas básicas: escolha, classificação, ordenação e descrição.

Neste trabalho é considerada a problemática de classificação (P.ß), que consiste em formular o problema de decisão de tal forma que distribua cada alternativa de A para uma categoria predefinida. O método ELECTRE TRI é destinado a este tipo de problemática e será descrito a seguir.

\subsection{ELECTRE TRI}

O ELECTRE TRI é um método de Sobreclassificação e constitui um dos métodos da família ELECTRE (Elimination and Choice Translating algorithm), que é composta pelos métodos ELECTRE I, II, III, IV, IS e TRI. Os métodos de Sobreclassificação, também denominados métodos de subordinação (termo em inglês: outranking), fundamentam-se na construção de uma relação de sobreclassificação que incorpora as preferências estabelecidas pelo decisor diante dos problemas e das alternativas disponíveis. Segundo Roy (1974), a relação de sobreclassificação $\mathrm{S}$ é uma relação binária definida em A tal que aSb se a é pelo menos tão boa quanto b. Essa relação não exige a transitividade.

O método ELECTRE TRI considera a problemática $\beta$ (P. $\beta$ ), que classifica as diversas alternativas para a solução de um problema por meio da comparação de cada alternativa potencial com uma referência estável (padrão/alternativa de referência).

Sendo conhecidas as alternativas de referência (ou perfis): $b_{1}, b_{2}, \ldots, b_{p}$ e os critérios: $\mathrm{j}_{1}, \mathrm{j}_{2}, \ldots, \mathrm{j}_{\mathrm{n}}$ definem-se $(\mathrm{p}+1)$ categorias: $\mathrm{C}_{1}, \mathrm{C}_{2}, \ldots, \mathrm{C}_{\mathrm{n}}$. Para um dado critério $\mathrm{j}$, a alternativa $a$ será localizada em uma determinada categoria, em função de sua avaliação $\mathrm{g}_{\mathrm{i}}(a)$.

O ELECTRE TRI trata de problemas que são modelados por uma família de pseudocritérios, no qual os limiares de preferência e indiferença $p j\left(b_{h}\right)$ e $q j\left(b_{h}\right)$ constituem as informações intracritérios. Assim, $q j\left(b_{h}\right)$ especifica a maior diferença gj $(a)$-gj $\left(b_{h}\right)$, que preserva a indiferença entre $a$ e $b_{h}$ no critério gj e $p j\left(b_{h}\right)$ representa a menor diferença gj $(a)$-gj $\left(b_{h}\right)$, compatível com uma preferência de a no critério gj.

O método calcula um índice de credibilidade $\sigma\left(b_{h}, a\right)$ que permite avaliar como a alternativa $b_{h}$ supera a alternativa $a . \sigma\left(a, b_{h}\right) \in[0,1]$ e a afirmação $a S b_{h}$ é considerada válida se $\sigma\left(a, b_{h}\right) \geq \lambda$, em que $\lambda$ é o nível de corte situado no intervalo entre 0,5 e 1 . Este índice é encontrado em função da concordância e da discordância entre os pares de alternativas, sendo calculado como segue (fórmula 1).

$$
\sigma\left(a, b_{h}\right)=C\left(a, b_{h}\right) \prod_{j \in F} \frac{1-d_{j}\left(a, b_{h}\right)}{1-C\left(a, b_{h}\right)}, \text { onde } \bar{F}=\left\{j \in F: d_{j}\left(a, b_{h}\right)>C\left(a, b_{h}\right)\right\}
$$

A classificação das alternativas é feita mediante um procedimento pessimista ou otimista. Mais detalhes do método ELECTRE TRI podem ser encontrados em Belton (2002), Vincke (1992) e Yu (1992). Também são encontradas na literatura diversas aplicações do 
ELECTRE TRI tais como: Aplicação em Recursos Hídricos, Tratamento de Esgoto, Agricultura, Irrigação, Sistemas de Informação Geográfico, Avaliação de Programas de Pós-graduação, dentre outros. (Raju et al., 2000; Joerin et al., 2001; Dias \& Climaco, 2000; Miranda \& Almeida, 2003; Almeida \& Costa, 2003).

\subsection{Modelo de inferência do ELECTRE TRI}

Ao usar o ELECTRE TRI, uma das maiores dificuldades do analista é quando ele interage com o decisor para elicitar os vários parâmetros de preferências. $\mathrm{O}$ analista deve determinar valores de diversos parâmetros (os perfis que definem os limites entre as categorias, pesos, limiares...), que são usados para construir um modelo de preferência do decisor. Mesmo que esses parâmetros possam ser interpretados, é difícil fixar diretamente valores para eles e ter um claro entendimento global das implicações que esses valores têm para o resultado do modelo.

Exceto em alguns casos específicos, não é natural supor que o decisor possa explicitamente dar valores a esses parâmetros, visto que são diferentes dos termos naturais com que o decisor expressa suas preferências.

Mousseau \& Slowinski (1998) propuseram um modelo de inferir os parâmetros do ELECTRE TRI com uma análise de exemplos atribuídos pelo decisor, isto é, dos julgamentos holísticos. Essa abordagem representa o paradigma da desagregação das preferências que visa extrair a informação implícita contida nos julgamentos holísticos dado por um decisor.

O objetivo dessa abordagem é achar um modelo do ELECTRE TRI compatível com os exemplos atribuídos pelo decisor. Os exemplos atribuídos dizem respeito a um subconjunto $\mathrm{A}^{*} \subset \mathrm{A}$ de alternativas para as quais o decisor tem preferências claras, isto é, alternativas em que o decisor pode facilmente especificar uma categoria, levando em consideração suas avaliações em todos os critérios. A compatibilidade entre o modelo do ELECTRE TRI e os exemplos da atribuição é compreendida como uma habilidade do método ELECTRE TRI de usar o modelo de inferência para atribuir novamente as alternativas de $\mathrm{A}^{*}$ da mesma maneira que o decisor fez. Para o modelo de inferência ter representatividade, o subconjunto de $A^{*}$ deve ser definido de tal modo que o número de alternativas definidas nas categorias seja igual ou suficientemente grande para "conter informação suficiente".

Para minimizar as diferenças entre as atribuições feitas pelo decisor e as realizadas pelo ELECTRE TRI, um procedimento de inferência dos parâmetros é usado. O resultado do ELECTRE TRI é denotado por $\mathrm{M}_{\pi}$.

Para determinar o modelo $\mathrm{M}_{\pi}$ que melhor atribui os exemplos fornecidos pelo decisor, Mousseau \& Slowinski (1998) formularam um problema de otimização, como apresentado a seguir:

$$
\alpha+\varepsilon \sum_{a_{k} \in A^{*}}\left(x_{k}, y_{k}\right) \rightarrow \max , \quad \alpha \leq x_{k}, \quad \forall a_{k} \in A^{*} \text { e } \alpha \leq y_{k}, \quad \forall a_{k} \in A^{*}
$$

Sujeito a:

$$
\frac{\sum_{j=1}^{m} k_{j} c_{j}\left(a_{k}, b_{h k-1}\right)}{\sum_{j=1}^{m} k_{j}}-x_{k}=\lambda
$$




$$
\begin{aligned}
& \frac{\sum_{j=1}^{m} k_{j} c_{j}\left(a_{k}, b_{h k}\right)}{\sum_{j=1}^{m} k_{j}}+y_{k}=\lambda \\
& \lambda \in[0.5,1] \\
& g_{j}\left(b_{h+1}\right) \geq g_{j}\left(b_{h}\right)+p_{j}\left(b_{h}\right)+p_{j}\left(b_{h+1}\right), \forall j \in F, \forall h \in B \\
& p_{j}\left(b_{h}\right) \geq q_{j}\left(b_{h}\right), \forall j \in F, \forall h \in B \\
& k_{j} \geq 0, q_{j}\left(b_{h}\right) \geq 0, \forall j \in F, \forall h \in B
\end{aligned}
$$

O modelo considera apenas o caso do procedimento pessimista do ELECTRE TRI, em que uma alternativa $a_{\mathrm{k}}$ é classificada para a categoria $\mathrm{C}_{\mathrm{h}}\left(\mathrm{b}_{\mathrm{h}-1}\right.$ e $\mathrm{b}_{\mathrm{h}}$ sendo os perfis inferiores e superiores de $\mathrm{C}_{\mathrm{h}}$, respectivamente), se, e somente se, $\sigma_{\pi}\left(a_{k}, b_{h-1}\right) \geq \lambda$ e $\sigma_{\pi}\left(a_{k}, b_{h}\right)<\lambda$. Para representar esta situação são inseridas duas variáveis de folga $x_{\mathrm{k}}$ e $\mathrm{y}_{\mathrm{k}}$ irrestritas em sinal tal que $\sigma_{\pi}\left(a_{k}, b_{h-1}\right)-x_{k}=\lambda$ e $\sigma_{\pi}\left(a_{k}, b_{h}\right)+y_{k}=\lambda$. Considerando o conjunto de alternativas $\mathrm{A}^{*}=\left\{a_{1}, a_{2}, \ldots, a_{\mathrm{k}}, \ldots, a_{\mathrm{n}}\right\}$ e supondo que o decisor classificou a alternativa $a_{\mathrm{k}}$ na categoria $\mathrm{C}_{\mathrm{hk}}, \forall a_{\mathrm{k}} \in \mathrm{A}^{*}$. $\mathrm{O}$ modelo $\mathrm{M}_{\pi}$ será consistente com a atribuição feita pelo decisor, se, e somente se, $\mathrm{x}_{\mathrm{k}} \geq 0$ e $\mathrm{y}_{\mathrm{k}} \geq 0, \forall a_{\mathrm{k}} \in \mathrm{A}^{*}$. A função objetivo deve então minimizar os valores das variáveis de folga $x_{k}$ e $y_{k}$. (fórmula 2)

As restrições (3) e (4) do problema de otimização apresentam uma aproximação do índice de credibilidade $\left[\sigma_{\pi}\left(a_{k}, b_{h}\right)\right.$ e $\left.\sigma_{\pi}\left(a_{k}, b_{h-1}\right)\right]$, que está em função apenas do índice de concordância, não sendo considerada a discordância, neste caso. As restrições (5), (6), (7) e (8) são condições essenciais do método ELECTRE TRI.

Outros estudiosos também utilizaram problemas de otimização para a inferência de alguns parâmetros do ELECTRE TRI. (Mousseau et al., 2001; Mousseau \& Dias, 2004; Dias et al., 2002).

\section{Modelo de Decisão Multicritério para Classificação de Estoques}

A seguir é apresentado o esquema do modelo de decisão para classificação itens de estoques da construção civil. O modelo, ora proposto, recomenda que sejam classificados os itens do estoque de tal forma que sejam estabelecidas classes de artigos. Tal procedimento vem a facilitar não só a tomada das decisões, a respeito da política de estoques, a qual deverá ser sempre a mesma para cada classe, como auxiliar na gerência dos materiais.

A gerencia de materiais envolve determinar o nível do inventário, que deve considerar as políticas de reposição sobre a natureza dos custos associados e trade off, envolvendo os custos de obtenção. Isso se relaciona com a maneira como a operação está configurada.

\subsection{Descrição do modelo de classificação de estoques}

A construção de classes para o controle dos itens de estoque pode ser realizada com a utilização de métodos multicritério de apoio a decisão, a qual considera mais de um critério simultaneamente. A estrutura do modelo é apresentada na Figura 1. 
O modelo é aplicado à indústria da construção civil, podendo, no entanto, ser utilizado em qualquer outra atividade econômica; portanto, a descrição dos passos a seguir variará de acordo com o setor ao qual será aplicado o modelo.

Para aplicação na construção civil, o modelo segue, portanto, as etapas descritas a seguir e apresentadas na Figura 1.

O modelo tem início com o levantamento dos itens de estoque do estudo: realizado por meio do estudo da composição de materiais de cada atividade do projeto; seleção dos critérios de avaliação apropriados: definido pelo responsável pelo estoque de materiais e determinante para a criação de famílias, em que serão formuladas políticas de estoques; coleta dos dados necessários para os critérios para todas as alternativas: todos os dados coletados devem ser validados, e as unidades dos dados devem ser consistentes; determinar o número de categorias: deve-se selecionar o ponto de ruptura relacionado, isto é, a regra de classificação para cada classe; determinação do método multicritério a ser aplicado: devem ser consideradas a estrutura de preferências do decisor, a problemática de decisão e contexto; aplicação do método de apoio multicritério a decisão; classificação dos artigos em grupos e por fim a execução dos ajustes necessários de acordo com algumas outras considerações.

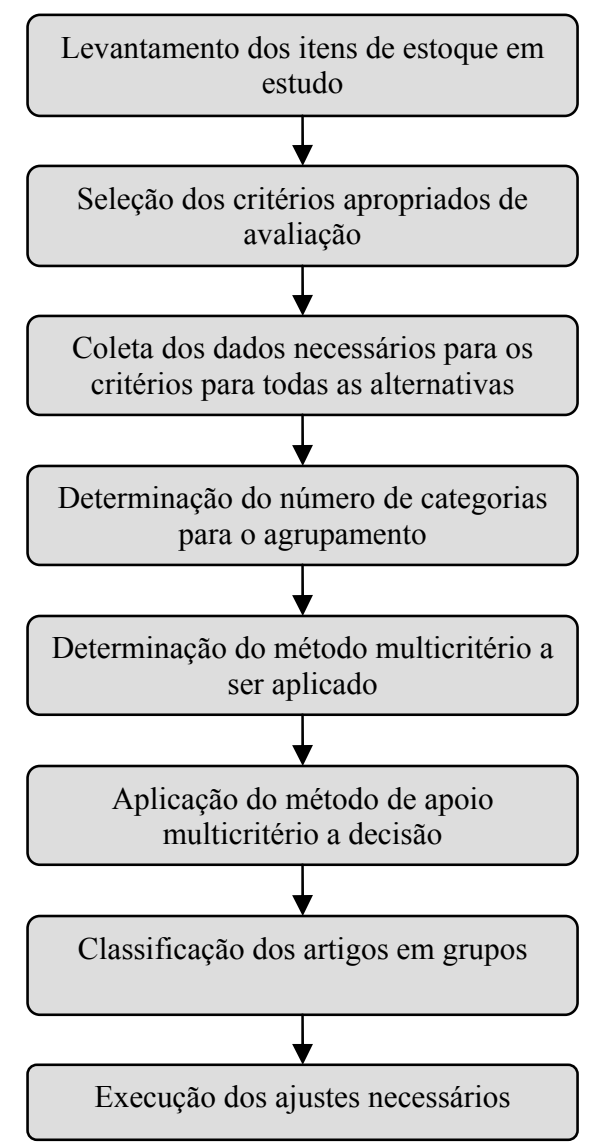

Figura 1 - Modelo de classificação de itens de estoque. 
Estudos no campo da administração de materiais concluíram que um efetivo sistema de administração de materiais irá resultar em 6 a 8\% de melhora na produtividade, aumento do fluxo de caixa, redução do volume de excesso de materiais, redução de recursos humanos para a administração de materiais, melhora na performance do fornecedor, redução física do armazém, realização de compras com descontos, minimização do impacto de mudança de pedidos e diminuição dos projetos atrasados (CII, 1988).

\subsection{Estruturação do problema}

A correta aplicação de qualquer modelo de decisão requer uma análise da estruturação do problema. Essa fase é de extrema importância para o processo decisório, pois, para se compreender a complexidade de uma situação em que se pretende intervir, torna-se necessário começar pela análise e caracterização da situação problemática em causa e pelos subsistemas inter-relacionados, o que envolve a identificação de atores, elementos característicos do problema, alternativas, critérios de avaliação e caracterização da problemática em questão, concluindo com a escolha do método multicritério mais adequado e do número de categorias.

\subsubsection{Elementos característicos para a avaliação}

Para a realização da caracterização do problema, alguns dados deverão ser coletados da empresa para que, com essas informações, seja possível avaliar as alternativas à luz de cada um dos critérios estabelecidos, conforme o modelo apresentado na Figura 1.

Os principais dados a serem levantados, em função dos critérios de avaliação, são:

- Composição de custo unitário da obra estudada;

- Informações sobre a gestão de materiais da empresa;

- Levantamento do fluxo de informações;

- Tempo de entrega médio dos materiais pelos fornecedores.

Nesta fase preliminar de estruturação do problema, foi detectado que esses eram os fatores mais relevantes a serem considerados para análise do problema.

\subsubsection{Alternativas}

As alternativas do modelo são os materiais definidos no orçamento da obra estudada. Cada elemento do projeto é materializado por meio de atividades que consomem diversos recursos, dos quais dois são comuns a todas elas, quaisquer que sejam: a mão-de-obra nelas empregada e o custo dos diferentes insumos que as compõem, servindo o custo, no caso, de denominador comum de todos os insumos utilizados.

No Brasil, é usual expressar os insumos gastos em função do seu custo traduzido em moeda, construindo o somatório desses custos o planejamento de custos do projeto, ou seja, a sua estimativa de custos ou orçamento, servindo esse como referencial para o controle do empreendimento (Limmer, 1997).

A discriminação orçamentária da obra é caracterizada pelos diferentes tipos de custos nela incorridos, correspondentes às quantidades dos diversos tipos de insumos a ser consumidos. Por meio da discriminação orçamentária da obra é possível, então, levantar os materiais (insumos materiais) que serão utilizados, como alternativas para o modelo. 


\subsubsection{Critérios de avaliação}

Segundo Roy (1996), chama-se critério uma "ferramenta" que permite comparar alternativas de acordo com um particular "eixo de significância" ou com um "ponto de vista". Mais precisamente, um critério é uma função de valor real sobre um conjunto " $\mathrm{A}$ " de alternativas tal que permita comparar duas alternativas a e b, de acordo com um ponto de vista particular sobre uma base única entre dois números $\mathrm{g}(\mathrm{a})$ e $\mathrm{g}(\mathrm{b})$.

A família de critérios deve representar de forma clara e correta o juízo de valores do decisor e deve ser efetuada com base nos objetivos do decisor, envolvendo, portanto, sua participação.

Foram definidos três critérios pelo decisor que buscou com eles avaliar os aspectos financeiros, de transporte e operacional dos materiais. De acordo com a literatura esses aspectos são considerados relevantes para o tratamento de gestão de estoques (Cohen \& Ernst, 1988; Flores et al., 1992; Flores \& Whybark, 1986 e 1987; Guvenir \& Erel, 1998; Moreira, 1996). Após diversas discussões com o decisor, num processo de brainstormig, foi possível estabelecer os critérios de avaliação que representassem significativamente esses aspectos.

A literatura, por sua vez, tem tratado o processo de estruturação de problemas por meio do uso de mapas cognitivos, que geralmente envolvem um processo de discussão com apoio de ferramentas visuais, e que é muito relevante para o caso de grupo de decisores (Rosenhead \& Mingers, 2004).

Os seguintes critérios foram definidos:

C1: Valor do investimento

Esse é um critério financeiro e mensurável. O valor do investimento em materiais é importante tanto para o fluxo de caixa da empresa como para o controle de armazenagem (para evitar roubos e estragos). Esse critério é avaliado pelo orçamento discriminado da obra e é calculado pela multiplicação da quantidade de materiais pelo custo unitário.

C2: Lead time

É o tempo médio estimado pelo fornecedor para a entrega dos materiais após o pedido de compra. Esse critério é importante visto que os materiais que possuem um lead time grande devem ser requisitados pelo engenheiro com antecipação para que o material não falte na obra. $\mathrm{O}$ valor do lead time é fornecido pelo engenheiro da obra.

Esse valor não é precisamente sabido. É fornecido pelo usuário, porém é satisfatório para a classificação de estoques (Flores \& Whybark, 1986 e 1987; Flores et al., 1992; Lenard \& Roy, 1995).

C3: Impacto da falta

Esse critério procura representar o fator operacional dos materiais, isto é, avaliar o impacto da falta do material na operação da obra. Trata-se de um fator importante, tendo em vista que materiais com custo baixo normalmente não recebem o devido apreço do engenheiro e isso pode ocasionar atraso na produção caso eles faltem na obra. Por se tratar de um critério subjetivo, foram adotados os números de serviços com que os materiais estão relacionados para avaliar o impacto da falta. Quanto maior esse número, mais importante ele é para a operação. Esse número é avaliado olhando-se a composição de custo unitária de cada serviço da obra em que o material está inserido. 
É importante destacar que as avaliações das possíveis alternativas para cada um dos critérios são representadas, naturalmente, por uma escala de razão, já que são compostas das respectivas unidades de medida, Custo em Reais, Tempo em dias e número de serviço (número inteiro).

\subsubsection{Escolha do método multicritério}

Os modelos quantitativos podem ser caracterizados em razão de poderem ser investigados pelas técnicas de análise matemática. A aplicação dessas técnicas é especialmente necessária para se obter de algum modo uma decisão estruturada para o problema indicado. Para se obter um modelo quantitativo, todas as variáveis têm de ser restringidas para serem cardinalmente mensuráveis. Além disso, o modelo deve ser bastante simples de modo que a matemática possa ser aplicada com sucesso.

A escolha do método empregado depende do tipo de problema em análise, do contexto estudado, dos atores envolvidos, da estrutura de preferências e do tipo de resposta que se deseja alcançar, ou seja, qual a problemática de referência (Gomes et al., 2002). Em muitos casos, um modelo quantitativo descreve claramente apenas uma seção pequena do problema real que está sendo investigado. Assim, a qualidade de uma decisão dependerá freqüentemente do modelo quantitativo usado.

Neste caso específico, está se considerando uma estrutura de preferências de pseudo-critério, baseado nos modelos de sobreclassificação que se caracterizam por não apresentarem compensação entre os critérios de avaliação. O método ELECTRE TRI se adequa a este tipo de problema, sendo também compatível com a escala dos critérios considerados (cardinal), além de atender ao problema de classificação.

Para o caso em estudo, a problemática é de classificação, uma problemática $\mathrm{P} \beta$ e para tal foi escolhido o método ELECTRE TRI, que se aplica perfeitamente ao caso em estudo.

Ao usar o ELECTRE TRI, o decisor deve determinar valores de diversos parâmetros (os perfis que definem os limites entre as categorias, pesos, limiares...) que, mesmo que possam ser interpretados, são difíceis de fixar diretamente e ter um claro entendimento global das implicações que esses valores têm para o resultado do modelo. Para esses casos, em que o decisor não possa dar valores explicitamente aos parâmetros do ELECTRE TRI, é proposto o modelo de Mousseau \& Slowinski (1998) para inferir os parâmetros do ELECTRE TRI com uma análise de exemplos atribuídos pelo decisor, isto é, dos julgamentos holísticos.

Então, para a aplicação do modelo proposto, com o uso do ELECTRE TRI, o analista teria duas opções de acordo com o perfil do decisor. Se o decisor for capaz de determinar os parâmetros do ELECTRE TRI, será utilizado o modelo do método normalmente, caso contrário, isto é, se o decisor não for capaz de estabelecer esses parâmetros, será utilizado o modelo de inferência de parâmetros proposto por Mousseau \& Slowinski (1998), e com os resultados dos parâmetros desse modelo, será utilizado o método ELECTRE TRI. Este trabalho apresenta a situação em que o decisor não é capaz de estabelecer os pesos dos critérios.

A Figura 2 ilustra essa situação. 


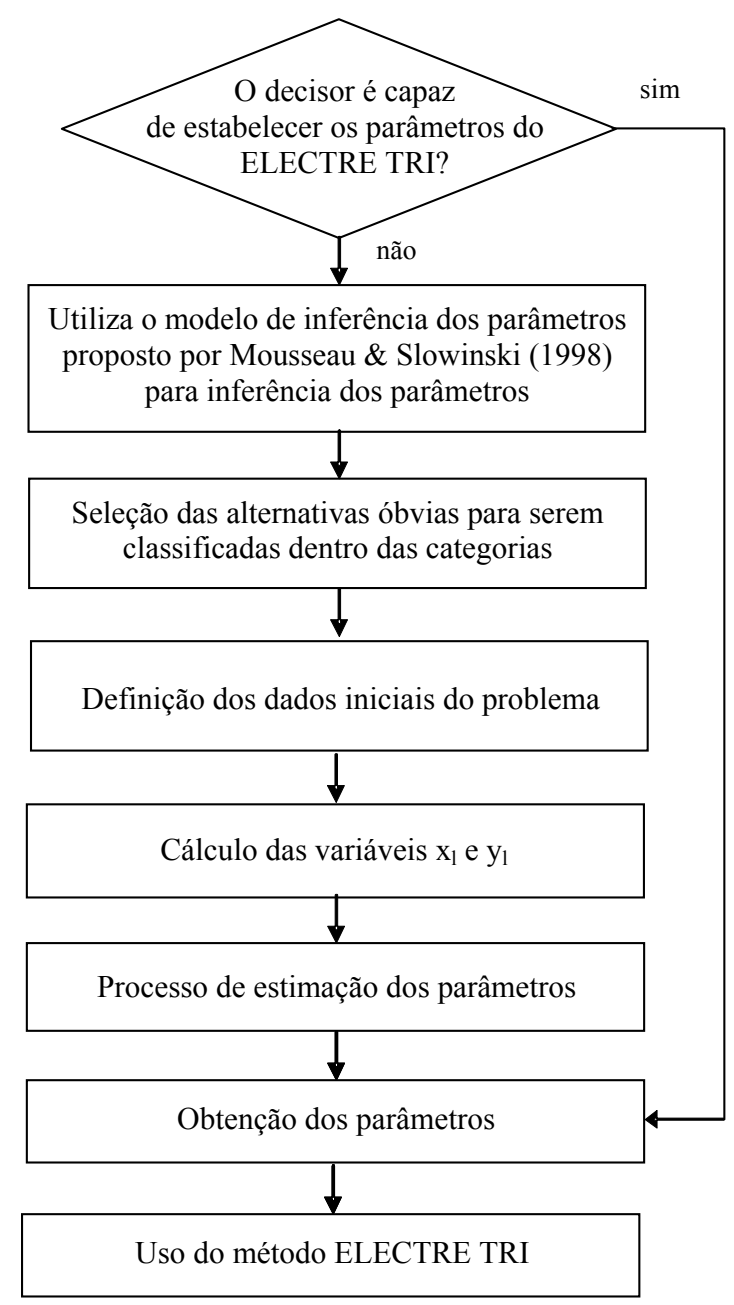

Figura 2 - Fluxo de definição dos parâmetros do ELECTRE TRI.

\subsubsection{Número de categorias}

Em construção civil, são utilizadas normalmente três práticas gerenciais relativas aos materiais.

Para materiais mais simples do ponto de vista de tempo de entrega, custo e impacto de falta, adota-se a prática de comprá-los em grande quantidade e estocá-los na obra, justamente pela simplicidade que os materiais apresentam, não exigindo do engenheiro uma atenção constante.

Há os materiais que são mais complicados, seja pelo alto valor, seja pelo longo tempo de entrega, e/ou dependência dele em vários serviços, de maneira que sua falta causa interrupção na obra, o que faz com que o engenheiro estude caso a caso o sistema de compra que será utilizado para cada material, de acordo com os empecilhos que esses materiais possuem, e daí demandam uma atenção constante do engenheiro. 
Existem, igualmente, os materiais que estão entre esses dois casos e que são pedidos de acordo com a fase da obra e da necessidade.

Nesse caso, pode-se verificar que, na prática, conta-se com três categorias para a classificação dos materiais, o que irá determinar a forma como o engenheiro irá definir as políticas de compras, sendo uma categoria correspondente aos materiais "mais importantes" e que exigem atenção enorme do engenheiro $(\mathrm{K}+)$, os materiais "menos importantes" (K-) e os que ficam no nível intermediário (K?).

Vale destacar que o escopo do trabalho prevê uma visão macro dos materiais, dividindo-os em três classes sob a ótica da visão multicritério. Posteriormente há de se fazer um estudo micro de cada uma dessas classes para a análise das políticas de reposição que serão adotadas respondendo às perguntas do quando comprar e do quanto comprar.

Nesse estudo micro deverá ser analisado o relacionamento desses materiais com a Rede PERT (Program Evaluation and Review Technique - Técnica de Revisão e Avaliação de Programa), o contrato que terá de ser feito com os fornecedores para uma grande quantidade de materiais que serão utilizados durante toda a obra e outros detalhes. O detalhamento desse trabalho está no nível tático, de extrema importância para o gerenciamento dos materiais da obra, pois é a partir dessa categorização que poderá ser analisada a política a ser adotada, a qual compreende um trabalho de nível operacional.

Então, de acordo com o que foi adotado na prática, os materiais serão qualificados pelo ELECTRE TRI em três grupos, mas nada impede que, num caso particular, mais classes sejam adicionadas para uma obra específica ou para um outro caso fora do contexto da construção civil.

\section{Aplicação do Modelo em Empresa Construtora}

\subsection{Descrição da empresa}

O modelo foi aplicado numa empresa construtora e incorporadora certificada com ISO 9001/2000, classificada como de médio porte, segundo o SEBRAE (2004). Conta com 10 empregados no escritório principal, enquanto nas obras existem aproximadamente 250 empregados.

A construtora já realizou mais de duzentos empreendimentos para os clientes públicos e particulares e na época da realização do estudo possuía três obras em andamento. A obra alvo deste estudo de caso é composta de seis blocos, tendo cada um quatro pavimentos assim distribuídos: um térreo e três pavimentos-tipo. Cada pavimento-tipo possui oito apartamentos, medindo cada um $34 \mathrm{~m}^{2}$.

A gestão de materiais é de responsabilidade do engenheiro da obra. O estoque é avaliado diariamente, quando são solicitados pedidos de compras de materiais. Esses pedidos são, geralmente, de urgência o que constantemente ocasiona atrasos na entrega dos materiais, atrasando assim o cronograma. Não existe, portanto, uma sistemática de controle de materiais.

A empresa, todavia, tem uma sistemática para a realização de pedidos de compras. Todos materiais necessários na obra têm de ser solicitados por uma requisição de materiais. No entanto, não existe um procedimento formal para a identificação das necessidades de materiais. Há um problema evidente no controle de estoque de materiais, com problemas de falta de material na obra e compras sem economia. 


\subsection{Aplicação do modelo}

Para o levantamento dos materiais, foram avaliados os serviços da obra com as respectivas composições de custos unitários, e daí foram retirados os itens em estoque que serão classificados, isto é, que participarão do modelo de decisão.

As avaliações das alternativas em relação aos critérios, tanto em valor absoluto como em importância relativa, merecem uma atenção especial, por se tratar do instrumento pelo qual são gerados os dados para o modelo. A relação dos materiais e suas respectivas avaliações está apresentada na Tabela A1, no Apêndice 1. As alternativas foram codificadas pela letra A e numeradas de A1 a A81.

\subsubsection{Aplicação do método ELECTRE TRI $M_{\pi}$}

Ao usar o método ELECTRE TRI para classificação dos itens em estoque, cabe ao engenheiro da obra (decisor) determinar valores de diversos parâmetros (os perfis que definem os limites entre as categorias, pesos, limiares...), que mesmo que possam ser interpretados, é difícil fixá-los diretamente e ter um claro entendimento global das implicações que esses valores têm para o resultado do modelo.

Diante desta dificuldade, o problema de gestão de materiais pode ser apoiado pelo modelo proposto por Mousseau \& Slowinski (1998) para inferir os parâmetros do ELECTRE TRI. O estudo é realizado por meio de uma análise de exemplos atribuídos pelo decisor, isto é, por julgamentos holísticos.

A aplicação de tal procedimento no contexto da construção civil é importante, visto que, além da dificuldade por parte do engenheiro (decisor) no estabelecimento dos parâmetros do modelo, há que se considerar um grande número de itens a serem controlados (alternativas), que favorecem o uso de modelo de inferência.

Assim, este estudo tem a pretensão de mostrar a aplicabilidade desse modelo para os casos em que os parâmetros do ELECTRE TRI não possam ser estabelecidos pelo decisor e as implicações dos resultados inferidos em relação aos diferentes exemplos atribuídos pelo mesmo decisor.

Cabe ressaltar que uma aplicação direta do modelo de Mousseau \& Slowinski (1998) pode levar a resultados não satisfatórios, sendo necessário um estudo preliminar para decidir quais alternativas (exemplos) serão consideradas como base para a avaliação global.

Para que o modelo tenha representatividade, o subconjunto $A^{*}$ de alternativas deve ser definido tal que o número de alternativas definidas nas categorias seja igual ou suficientemente grande para conter uma informação suficiente. Além disso, para as alternativas escolhidas o decisor deve ter preferências claras, isto é, deve especificar uma categoria para a alternativa, considerando suas avaliações em todos os critérios. Em alguns casos pode ser importante fazer um estudo estatístico preliminar para decidir sobre as alternativas exemplo a serem avaliadas globalmente pelo decisor.

Essa avaliação global foi realizada com as alternativas da Tabela 1, que foram facilmente classificadas pelo decisor dentro das respectivas categorias. 
Tabela 1 - Matriz de classificação das alternativas.

\begin{tabular}{|c|c|c|c|c|}
\hline Alternativas & CI & LT & IF & Categoria \\
\hline A60 & $13.805,6$ & 7 & 14 & 3 \\
\hline A70 & $32.530,06$ & 7 & 18 & 3 \\
\hline A16 & $11.503,2$ & 5 & 1 & 2 \\
\hline A77 & $3.685,82$ & 2 & 3 & 2 \\
\hline A48 & 392,83 & 2 & 1 & 1 \\
\hline A73 & $1.170,00$ & 1 & 1 & 1 \\
\hline
\end{tabular}

Para o cálculo da inferência dos parâmetros, alguns passos devem ser seguidos:

i. Definição dos dados iniciais do problema

- Os pesos foram todos definidos como iguais, com valor igual a 1;

- Os perfis iniciais foram definidos pela regra heurística proposta por Mousseau \& Slowinski (1998), como segue (9). Os valores estão apresentados na Tabela 2.

$g_{j}\left(b_{h}\right)=\frac{1}{2}\left\{\frac{\sum_{a_{i} \rightarrow C_{h-1}} g_{j}\left(a_{i}\right)}{n_{h-1}}+\frac{\sum_{a_{i} \rightarrow C_{h}} g_{j}\left(a_{i}\right)}{n_{h}}\right\}$

- Os limiares de preferência e indiferença foram fixados arbitrariamente em: $q_{j}\left(b_{h}\right)=0,1 g_{j}\left(b_{h}\right)$ e $p_{j}\left(b_{h}\right)=0,2 g_{j}\left(b_{h}\right)$ para o critério de custo de investimento e $q_{j}\left(b_{h}\right)=0,01 g_{j}\left(b_{h}\right)$ e $p_{j}\left(b_{h}\right)=0,02 g_{j}\left(b_{h}\right)$ para os critérios de lead time e impacto de falta. Estes últimos foram estabelecidos propositalmente pequenos devido à estrutura do critério. Esses valores encontram-se na Tabela 3;

- $\quad$ Nível de corte foi estabelecido em $\lambda=0.75$.

Tabela 2 - Perfis iniciais para os limites das categorias.

\begin{tabular}{|l|c|l|l|}
\hline & CI & LT & IF \\
\hline b2 & $15.381,16$ & 5,25 & 9 \\
\hline b1 & $4.187,96$ & 2,5 & 1,5 \\
\hline
\end{tabular}

Tabela 3 - Valores iniciais para os limiares.

\begin{tabular}{|c|c|l|l|}
\hline & CI & LT & IF \\
\hline $\mathrm{q}(\mathrm{b} 2)$ & $1.538,12$ & 0,0525 & 0,09 \\
\hline $\mathrm{p}$ (b2) & $3.076,23$ & 0,105 & 0,18 \\
\hline $\mathrm{q}$ (b1) & 418,8 & 0,025 & 0,015 \\
\hline $\mathrm{p}$ (b1) & 837,6 & 0,05 & 0,03 \\
\hline
\end{tabular}

ii. Cálculo das variáveis xk e yk

Os valores iniciais de xk e yk são apresentados na Tabela 4 e são calculados de acordo com o procedimento apresentado por Mousseau \& Slowinski (1998). 
Tabela 4 - Valores iniciais para as variáveis.

\begin{tabular}{|c|c|c|}
\hline & $\mathbf{X k}$ & $\mathbf{y k}$ \\
\hline A60 & 0,228 & 0,750 \\
\hline A70 & 0,250 & 0,750 \\
\hline A16 & $-0,083$ & 0,749 \\
\hline A77 & $-0,417$ & 0,750 \\
\hline A48 & 0,250 & 0,750 \\
\hline A73 & 0,250 & 0,750 \\
\hline
\end{tabular}

Como para as alternativas A16 e A77 os valores de xk são negativos, isso significa dizer que com esses dados iniciais o ELECTRE TRI classificaria essas alternativas de forma diferente da classificação realizada pelo decisor, já que, para a classificação coincidir, todos os valores de xk e yk teriam de ser positivos.

Com esses valores de parâmetros iniciais, as alternativas A16 e A17 seriam classificadas na categoria 1, enquanto o decisor as classificou na categoria 2.

Para o valor inicial de $\alpha$, que é definido como o menor valor entre xk e yk, tem-se: $\alpha=-0,417$.

\section{iii. Inferência dos parâmetros}

De posse dos dados iniciais, a inferência dos parâmetros usando um problema de otimização é realizado pelo Solver do Microsoft Excel 2002. As variáveis do problema e as restrições estão apresentadas na seção 3.2. Também foi adicionada ao problema a seguinte restrição (10) já que nenhum critério é dominante nesse caso.

$$
k_{j} \leq 1 / 2 \sum_{i=1}^{m} k_{i}, \forall j \in F .
$$

Os valores dos parâmetros calculados pelo modelo são mostrados nas Tabelas 5 e 6 .

Tabela 5 - Valores "ótimos" dos perfis dos limites das categorias.

\begin{tabular}{|c|c|c|l|}
\hline CI & LT & IF & \\
\hline b2 & $15.381,16$ & 5,25 & 9 \\
\hline b1 & $4.187,96$ & 2,5 & 1,5 \\
\hline
\end{tabular}

Tabela 6 - Valores dos limiares "ótimos".

\begin{tabular}{|c|c|l|l|}
\hline CI & LT & \multicolumn{1}{|c|}{ IF } & \\
\hline $\mathrm{q}(\mathrm{b} 2)$ & $1.538,12$ & 0,0525 & 0,09 \\
\hline $\mathrm{p}(\mathrm{b} 2)$ & $3.076,23$ & 0,105 & 0,18 \\
\hline $\mathrm{q}(\mathrm{b} 1)$ & 418,8 & 0,025 & 0,015 \\
\hline $\mathrm{p}(\mathrm{b} 1)$ & 837,6 & 0,05 & 0,03 \\
\hline
\end{tabular}

Além disso, $\alpha=0, \lambda=0,5, \mathrm{k}_{1}=0,75 \mathrm{k}_{2}=0,75 \mathrm{k}_{3}=1,5$.

Os valores finais de xk e yk são mostrados na Tabela 7 .

O modelo obtido é capaz de classificar as alternativas $A^{*}$ de forma satisfatória. A classificação do modelo é consistente para todo $\lambda \in[0.5,1]$, o que prova a consistência do modelo. 
Tabela 7 - Valores finais de xk e yk.

\begin{tabular}{|c|c|c|}
\hline & xk & yk \\
\hline A60 & 0,483 & 0,500 \\
\hline A70 & 0,500 & 0,500 \\
\hline A16 & 0,000 & 0,499 \\
\hline A77 & 0,000 & 0,500 \\
\hline A48 & 0,500 & 0,500 \\
\hline A73 & 0,500 & 0,500 \\
\hline
\end{tabular}

\subsubsection{Análise dos resultados obtidos}

Os valores calculados foram $\mathrm{k} 1=0,75 \mathrm{k} 2=0,75 \mathrm{k} 3=1,5$, normalizando esses valores: $\mathrm{k} 1=0,25 \mathrm{k} 2=0,25 \mathrm{k} 3=0,5$. O que se observa é que o maior critério é o impacto de falta, coincidindo com a avaliação do decisor como critério mais importante. Os critérios de custo de investimento e lead time possuem a mesma importância de acordo com o modelo. Se o decisor tiver certeza de que o lead time possui uma importância maior que o custo de investimento, essa restrição pode ser imposta no modelo.

O limiar de veto foi definido de forma que a classificação do ELECTRE TRI para as categorias atribuídas pelo decisor inicialmente continuasse a mesma, e foi definido igual a $30 \%$ do valor dos perfis iniciais.

É importante observar que um estudo prévio para escolha das alternativas exemplo deve ser considerado, podendo ser realizado um estudo estatístico, visto que, se novas alternativas previamente classificadas pelo decisor fossem acrescentadas ao processo de inferência dos parâmetros, valores diferentes desses poderiam obtidos.

\subsection{Comentários sobre a aplicação}

O método ELECTRE TRI tem necessidade de elicitação de diversos parâmetros (perfis, limiares, pesos, nível de corte...) do decisor, que raramente consegue explicitá-los com clareza e consciente da influência que os parâmetros implicam no método. O uso do método ELECTRE TRI, neste caso em questão, requereria que todos esses aspectos fossem explicados além de ser necessária a realização de várias simulações para que o decisor pudesse perceber a influência dos parâmetros no modelo e assim obter segurança nos parâmetros por ele estabelecidos.

Nesse sentido, um modelo para inferência dos parâmetros empregando um problema de otimização foi utilizado, partindo de exemplos atribuídos pelo decisor em categorias, para a elicitação dos parâmetros a partir desses exemplos. Para que esse processo de inferência de parâmetros tenha consistência, o decisor precisa classificar as alternativas facilmente e elas precisam abranger o maior número de informações relevantes possível. Isso acontece, pois, se o decisor não tem certeza da categoria estabelecida para uma alternativa, todo o processo de inferência dos parâmetros será inválido, já que está partindo de classificações "incorretas" ou "com dúvidas". A mesma coisa acontece se as alternativas escolhidas não tiverem a abrangência de informações requerida pelos dados que serão posteriormente classificados pelos parâmetros inferidos. O modelo de inferência dos parâmetros foi realizado com todos esses cuidados para que não houvesse distorções no resultado. 
O processo apresentado oferece ao decisor mais uma alternativa em relação à sua escolha para a classificação dos materiais, já que pode optar por usar o método ELECTRE TRI com a parametrização fornecida por ele, nos casos possíveis, ou por aquela obtida pelo processo de inferência dos parâmetros a partir de um problema de otimização, podendo o decisor escolher aquela que o deixar mais "confiante" em relação a suas preferências, não obtendo nesse caso o "certo" e o "errado".

\section{Conclusões}

Este trabalho teve como objetivo apresentar o uso de métodos de apoio a decisão multicritério para a classificação dos itens de estoque da construção civil à luz de critérios estabelecidos pelo decisor.

O problema de gerenciamento de estoques em construção civil foi discutido, apresentando as principais características do setor. Os principais modelos utilizados na literatura para esse tipo de problema foram pesquisados e adaptados para o problema em questão.

Incorporar os múltiplos critérios no processo de Gestão de Estoques torna-se fundamental num momento em que as construtoras entram na concorrência global, com lucros cada vez menores, visto que os materiais representam 60 a $70 \%$ do valor global da obra. Posto isto, as políticas e objetivos estratégicos devem ser refletidos desde a definição de critérios de gerenciamento de materiais até as decisões de políticas de estoques.

A abordagem outranking (sobreclassificação), em especial o método ELECTRE TRI associado a um modelo de inferência foi adotado, o que revelou um grande potencial de aplicação em problemas desse contexto. O ELECTRE TRI é uma metodologia destinada para tratar problemática de classificação, adequado para esse problema e o modelo de inferência permite que o construtor possa utilizar o ELECTRE TRI sem estabelecer os parâmetros do modelo, que são de difícil interpretação física. Isso faz com que o construtor tenha a opção de usar uma metodologia de apoio a decisão mais sofisticada para a gestão de estoque. Vale ressaltar que o decisor irá se deparar com esse problema diversas vezes, tornando o problema de gestão de estoques uma tarefa repetitiva. O uso de um modelo estruturado e de fácil aplicação é fundamental para apoiar o gerente nesta tarefa.

Um estudo de caso em uma obra de construção de prédio residencial revelou que o uso dessa modelagem para tratar o problema de gestão de estoques gera resultados bastante satisfatórios.

Talvez a maior dificuldade na área de gerenciamento de estoques esteja em considerar aspectos que, a priori, não podem ser medidos monetariamente ou não sejam facilmente obtidos, mas que os decisores consideram implicitamente em suas tomadas de decisão de classificação de estoques para compras. E é justamente por negligenciar a relação entre "tomada de decisão" e "apoio a decisão" que aparece a principal dificuldade, qual seja, a de entender a decisão como um processo do qual fazem parte as características objetivas das "ações" e as perspectivas subjetivas dos "decisores", em que os modelos multicritérios num processo de construção, baseado na estruturação, apóia a tomada de decisão.

Dessa forma, o modelo apresentado classificou ou materiais em três classes da obra, visando a um papel estratégico no setor de suprimentos em construção civil, o que constitui uma tendência nos dias atuais, mas que ainda não é uma realidade completamente reconhecida no setor. 


\subsection{Sugestões para futuros trabalhos}

O papel do setor de suprimentos na construção civil apresenta-se ainda repleto de falhas, merecendo por isso uma maior atenção dos estudiosos dessa temática. Abaixo estão agrupadas algumas sugestões para a elaboração de futuros trabalhos, utilizando-se o modelo de classificação de estoques:

- O modelo de inferência dos parâmetros pode ser aprofundado quanto ao aspecto do número de alternativas necessárias para sua aplicação, sendo realizado um estudo estatístico;

- Um estudo probabilístico poderia ser feito em relação à obtenção do lead time do fornecedor, garantindo maior precisão;

- Em relação à quantidade de agentes decisores, o problema pode ser analisado sob o enfoque da decisão em grupo, em que são colocados tanto os objetivos dos diretores da empresa quanto aqueles do gestor da obra;

- Um estudo operacional pode ser realizado a partir dessa classificação, utilizando-se a ligação entre o material e a rede PERT-CPM da obra, condições de restrição impostas por capacidade de armazenagem na obra, para decisões do quanto comprar e quando comprar.

\section{Agradecimentos}

Os autores agradecem ao CNPq e à CAPES pelo apoio parcial no financiamento deste estudo.

\section{Referências Bibliográficas}

(1) Agapiou, A. (1998). The changing role of builders merchants in the construction supply chain. Construction Management and Economics, 16, 351-361.

(2) Agrell, P.J. (1994). A multicriteria approach to concurrent engineering. International Journal of Production Economics, 34, 99-113.

(3) Almeida, A.T. \& Costa, A.P.C.S. (2003). Aplicações com métodos multicritério de apoio a decisão. Universitária, Recife.

(4) Barzilai, J. \& Golany, B. (1994). AHP rank reversal normalization and aggregation rules. INFOR., Ottawa, 32(2), May.

(5) Bell, L.C. \& Stukhart, G. (1987). Costs and Benefits of materials management system. Journal of Construction Engineering and Management, ASCE, 13, 222-234.

(6) Belton, V. \& Stewart, J. (2002). Multiple Criteria Decision Analysis - an Integrated Approach. Kluwer Academic Publishers, London.

(7) CII - Construction Industry Institute (1985). Attributes of Materials Management Systems. Texas A\&M University and Auburn University, Abril.

(8) CII - Construction Industry Institute (1986). Cost and Benefits of Materials Management Systems. Publication 7-1, Nov.

(9) CII - Construction Industry Institute (1988). Project Materials Management Primer. Bureau of Engineering Research Publication 7-2. The University of Texas at Austin, Nov.

(10) Cohen, M. \& Ernst, F. (1988). Multi-item classification and generic inventory stock control policies. Production and Inventory Management Journal, 29(3), 6-8. 
(11) Dias, L.; Mousseau, V.; Figueira, J. \& Clímaco, J. (2002). An agregation/disagregation approach to obtain robust conclusions with ELECTRE TRI. European Journal of Operational Research, 138, 332-348.

(12) Flores, B.E. \& Whybark, D.C. (1986). Multiple criteria ABC analysis. International Journal of Operations and Production Management, 6(3), 38-46.

(13) Flores, B.E. \& Whybark, D.C. (1987). Implementing multiple criteria ABC analysis. Journal of Operations Management, 7(1), 79-86.

(14) Flores, B.E.; Olson, D.L. \& Dorai, V.K. (1992). Management of multicriteria inventory classification. Mathematical and Computer Modelling, 16(12), 71-82.

(15) Gajpal, P.P; Ganesh, L.S. \& Rajendran, C. (1994). Criticality analysis of spare parts using the Analytic Hierarchy Process. International Journal of Production Economics, 35(1), 293-297.

(16) Garnett, N. (2000). Benchmarking for construction: theory and practice. Construction Management and Economics, 18, 55-63.

(17) Gomes, L.F.A.M.; Gomes, C.F.S. \& Almeida, A.T. (2002). Tomada de Decisão Gerencial: enfoque multicritério. Atlas, São Paulo. 264p.

(18) Gomes, C.F.S. \& Gomes, L.F.A.M. (1999). Uma Aplicação de Conjuntos Aproximativos ao Apoio Multicritério a negociação. Revista Pesquisa Naval, 12, 263-270.

(19) Gomes, L.F.A.M. (1996). O Controle de Estoques através da Classificação ABC Multicritério: Fundamentos e Exemplo de Aplicação. Pesquisa Naval, 14(2), 33-48.

(20) Guvenir, H.A. \& Erel, E. (1998). Multicriteria inventory classification using a genetic algorithm. European Journal of Operational Research, 105(1), 29-37.

(21) Hayes, R.H. (1998). Developing POM faculties for the 21st century. Production and Operations Management, 7(2), 94-98.

(22) Homaid, N.T.I. (2002). A comparative evaluation of construction and manufacturing materials management. International Journal of Project Management, 20, 263-270.

(23) Joerin, F.; Theriault, M. \& Musy, A. (2001). Using GIS and outranking multicriteria analysis for land-use suitability assessment. International Journal of Geographical Information Science, 15(2), 153-174.

(24) Lenard, J.D. \& Roy, B. (1995). Multi-item inventory control: a multicriteria view. European Journal of Operation Research, 87, 685-692, Abr.

(25) Lim, X. (1995). Construction productivity issues encountered by contractors in Singapore. International Journal of Project Management, 13(1), 51-8.

(26) Limmer, C.V. (1997). Planejamento, Orçamentação e Controle de Projetos e Obras. Livros Técnicos e Científicos, Rio de Janeiro.

(27) Lovejoy, W.S. (1998). Integrated operations: a proposal for operations management teaching and research. Production and Operations Management, 7(2), 106-124.

(28) Machuca, J.A.D. (1998). Improving POM learning: systems thinking and transparentbox business simulators. Production and Operations Management, 7(2), 210-227.

(29) Malakooti, B. (1989). A gradient-based approach for solving hierarchical multi-criteria production planning problems. Computers \& Industrial Engineering, 16(3), 407-417. 
(30) Marsh, J.W. (1985). Materials management: practical application in the construction industry. Cost Engineering, 27, 18-28.

(31) Miranda, C.M.G. \& Almeida, A.T. (2003). Avaliação de pós-graduação com método ELECTRE TRI: o caso de Engenharias III da CAPES. Revista Produção, 13(3), 101-112.

(32) Mohamed, S. (1996). Options for applying BPR in the Australian construction industry. International Journal of Project Management, 14(6), 379-85.

(33) Moreira, D.A. (1998). Administração da Produção e Operações. 3a. ed. Pioneira, São Paulo.

(34) Mousseau, V. \& Slowinski, R. (1998). Inferring an ELECTRE TRI Model from Assignment Examples. Journal of Global Optimization, 12, 157-174.

(35) Mousseau, V.; Figueira, J. \& Naux, J. (2001). Using assignment examples to infer weights for ELECTRE TRI method: some experimental results. European Journal of Operational Research, 130, 263-275.

(36) Mousseau, V. \& Dias, L. (2004). Valued outranking relations in ELECTRE providing manageable disaggregation procedures. European Journal of Operational Research, 156, 467-482.

(37) Pareto, V. (1946). Manual de economia política. Atalaya, Buenos Aires.

(38) Partovi, F.Y. \& Burton, J. (1993). Using the Analytic Hierarchy Process for ABC analysis. International Journal of Production and Operations Management, 13(9), 29-44.

(39) Partovi, F.Y. \& Hopton, W.F. (1994). The analytic hierarchy process as applied to two types of inventory problems. Production and Inventory management Journal, 35(1), 13-19.

(40) Raju, K.S.; Duckstein, L. \& Arondel, C. (2000). Multicriterion analysis for sustainable water resources planning: A case study in Spain. Water Resources Management, 14(6), 435-456.

(41) Roy, B. (1996). Multicriteria Methodology for Decision Aiding. Kluwer Academic Plublishers, Netherlands.

(42) Rosenhead, J. \& Mingers, J. (2004). Rational Analysis for a Problematic World Revisited: Problem Structuring Methods for Complexity, Uncertainty and Conflict. 2a. ed. John Wiley \& Sons Ltd., London.

(43) Sebrae (2004). Disponível em: <http://www.sebraesp.com.br/novo/pesquisa/download/ Informacoes basicas.doc $>$.

(44) Tung, S.L. \& Tang, S.L. (1998). A comparison of the Saaty's AHP and modified AHP for right and left eigenvector inconsistency. European Journal of Operational Research, Amsterdam, 106(1), p.123, Apr.

(45) Vargas, L.G. (1992). An Overview of the Analytic Hierarchy Process and its Applications. European Journal of Operational Research, 48, 2-8, 1990.

(46) Vincke, P. (1992). Multicriteria decision-aid. John Wiley \& Sons, Bruxelles.

(47) Yang, J.B.; Chen, C. \& Zhang, Z.J. (1988). The interactive decomposition method for multiobjective linear programming and its applications. Information and Decision Technologies, 14(3), 275-288. 
(48) Yoshimura, M.; Itani, K. \& Hituri, K. (1989). Integrated optimization of machine product design and process design. International Journal of Production Research, 27, 1241-1256.

(49) Yu, W. (1992). ELECTRE TRI - Aspects Méthodologiques et Guide d'Utilisation. Document du LAMSADE, 74, Université de Paris - Dauphine, Avril.

\section{Apêndice}

Tabela A1 - Tabela de avaliação das alternativas.

\begin{tabular}{|c|c|c|c|c|c|c|c|c|c|}
\hline ALTERNATIVAS & CÓD & CI (R\$) & $\begin{array}{c}\text { LT } \\
\text { dias }\end{array}$ & IF & ALTERNATIVAS & CÓD & CI (R\$) & $\begin{array}{c}\text { LT } \\
\text { dias }\end{array}$ & IF \\
\hline Aço CA-50 & $\mathrm{A}_{1}$ & 4201,14 & 8 & 6 & Grade Proteção Ferro & $\mathrm{A}_{42}$ & 270,00 & 8 & 1 \\
\hline Aço CA-50 (Armafer) & $\mathrm{A}_{2}$ & 22503,60 & 8 & 1 & Hidrômetro geral & $\mathrm{A}_{43}$ & 480,00 & 3 & 1 \\
\hline Aço CA-60 (Armafer) & $\mathrm{A}_{3}$ & 132723,13 & 8 & 13 & Hidrômetro individual & $\mathrm{A}_{44}$ & 12480,00 & 3 & 1 \\
\hline Aço CA-60 Tela & $\mathrm{A}_{4}$ & 57128,94 & 8 & 1 & Isopor & $\mathrm{A}_{45}$ & 40564,80 & 3 & 1 \\
\hline Aço CA-60 Tela Laje & $\mathrm{A}_{5}$ & 23315,10 & 8 & 4 & \begin{tabular}{|l|} 
Janela de Madeira \\
\end{tabular} & $\mathrm{A}_{46}$ & 65212,13 & 40 & 5 \\
\hline ÁGUA FRIA & $\mathrm{A}_{6}$ & 11765,88 & 3 & 1 & Laje treliçada & $\mathrm{A}_{47}$ & 114379,09 & 15 & 3 \\
\hline Aguarrás mineral & $\mathrm{A}_{7}$ & 660,35 & 2 & 4 & Líquido preparador & $\mathrm{A}_{48}$ & 392,83 & 2 & 1 \\
\hline Arame Galvanizado $\mathrm{n}^{\circ} 12$ & $\mathrm{~A}_{8}$ & 223,24 & 2 & 1 & Líquido selador PVA & $\mathrm{A}_{49}$ & 362,19 & 2 & 1 \\
\hline Arame recozido $\mathrm{n}^{\circ} 18$ & $\mathrm{~A}_{9}$ & 6117,65 & 2 & 25 & Lixa de madeira $\mathrm{n}^{\circ} 100$ & $\mathrm{~A}_{50}$ & 592,66 & 2 & 5 \\
\hline Areia Média & $\mathrm{A}_{10}$ & 8547,78 & 1 & 40 & LOUÇA 1 & $\mathrm{~A}_{51}$ & 1196,16 & 8 & 1 \\
\hline Argamassa Colante & $\mathrm{A}_{11}$ & 12,45 & 2 & 1 & \begin{tabular}{|l|l|} 
LOUÇA 2 \\
\end{tabular} & $\mathrm{~A}_{52}$ & 33690,24 & 8 & 1 \\
\hline Argamassa multiuso & $\mathrm{A}_{12}$ & 21830,37 & 3 & 4 & Madeira de Lei & $\mathrm{A}_{53}$ & 8525,52 & 15 & 1 \\
\hline Azulejo $15 \times 15 \mathrm{~cm}$ & $\mathrm{~A}_{13}$ & 187,39 & 1 & 1 & MAT ELÉTRICO 1 & $\mathrm{~A}_{54}$ & 7407,36 & 3 & 1 \\
\hline Barro de Aterro & $\mathrm{A}_{14}$ & 10,56 & 2 & 1 & MAT ELÉTRICO 2 & $\mathrm{~A}_{55}$ & 19185,39 & 15 & 1 \\
\hline Bloco "J" & $\mathrm{A}_{15}$ & 4425,73 & 5 & 1 & MAT ELÉTRICO 3 & $\mathrm{~A}_{56}$ & 11891,40 & 30 & 1 \\
\hline Bloco "U" $19 \mathrm{~cm}$ & $\mathrm{~A}_{16}$ & 11503,17 & 5 & 1 & MD & $\mathrm{A}_{57}$ & 1620,00 & 8 & 2 \\
\hline Bloco "U" 7cm & $\mathrm{A}_{17}$ & 3783,55 & 5 & 1 & Placa de Gesso & $\mathrm{A}_{58}$ & 6775,95 & 3 & 1 \\
\hline Bloco Cerâmico & $\mathrm{A}_{18}$ & 95872,04 & 5 & 1 & Placa de Obra & $\mathrm{A}_{59}$ & 1200,00 & 8 & 1 \\
\hline Bloco Cerâmico $11 \mathrm{~cm}$ & $\mathrm{~A}_{19}$ & 4964,54 & 5 & 1 & \begin{tabular}{|l|} 
Pontalete L.Rosa 3x3" \\
\end{tabular} & $\mathrm{A}_{60}$ & 13805,58 & 7 & 14 \\
\hline Bloco Cerâmico $14 \mathrm{~cm}$ & $\mathrm{~A}_{20}$ & 9735,21 & 5 & 1 & \begin{tabular}{|l|} 
Porta Comp $0,60 \times 2,10 \mathrm{~m}$ \\
\end{tabular} & $\mathrm{~A}_{61}$ & 3456,00 & 15 & 1 \\
\hline Bomba centrífuga & $\mathrm{A}_{21}$ & 2010,00 & 2 & 1 & Porta Comp 0,80x2,10m & $\mathrm{A}_{62}$ & 10560,00 & 15 & 1 \\
\hline Brita 19 & $\mathrm{~A}_{22}$ & 4100,00 & 2 & 16 & Porta Mad. $0,80 \times 2,10 \mathrm{~m}$ & $\mathrm{~A}_{63}$ & 7711,20 & 15 & 2 \\
\hline Brita 25 & $\mathrm{~A}_{23}$ & 5136,89 & 2 & 17 & Poste Concreto 100/8 & $\mathrm{A}_{64}$ & 810,00 & 3 & 1 \\
\hline Brita 38 & $\mathrm{~A}_{24}$ & 283,73 & 2 & 2 & \begin{tabular}{|l|} 
Prego $15 \times 15$ \\
\end{tabular} & $\mathrm{~A}_{65}$ & 87,00 & 2 & 1 \\
\hline CABOS & $\mathrm{A}_{25}$ & 25868,40 & 30 & 1 & Prego 2 1/2"x10 & $\mathrm{A}_{66}$ & 3991,30 & 2 & 22 \\
\hline Cal Hidratada & $\mathrm{A}_{26}$ & 1167,75 & 3 & 5 & Quadro Bomba & $\mathrm{A}_{67}$ & 390,00 & 3 & 1 \\
\hline Centro MM & $\mathrm{A}_{27}$ & 7200,00 & 30 & 3 & \begin{tabular}{|l|} 
Sarrafo Pinho de 1"x4" \\
\end{tabular} & $\mathrm{A}_{68}$ & 12026,74 & 7 & 16 \\
\hline Chapa compens $10 \mathrm{~mm}$ & $\mathrm{~A}_{28}$ & 5775,00 & 3 & 1 & Sika ou Vedacit & $\mathrm{A}_{69}$ & 1093,00 & 2 & 3 \\
\hline Chapa compens $12 \mathrm{~mm}$ & $\mathrm{~A}_{29}$ & 11018,01 & 3 & 14 & Tábua L.Rosa 1"x12" & $\mathrm{A}_{70}$ & 32530,06 & 7 & 18 \\
\hline Chuveiro plástico 3/4" & $\mathrm{A}_{30}$ & 370,56 & 3 & 1 & Tábua L.Rosa 1"x6" & $\mathrm{A}_{71}$ & 4640,58 & 7 & 1 \\
\hline Cimento Branco & $\mathrm{A}_{31}$ & 6,01 & 2 & 1 & Tábua L.Rosa 1"x9" & $\mathrm{A}_{72}$ & 2633,04 & 7 & 1 \\
\hline Cimento Portland & $\mathrm{A}_{32}$ & 53160,46 & 2 & 39 & Tampa Reservatório & $\mathrm{A}_{73}$ & 1170,00 & 1 & 1 \\
\hline Cumeeira fibrocimento & $\mathrm{A}_{33}$ & 411,38 & 1 & 1 & Telha canal & $\mathrm{A}_{74}$ & 14190,34 & 2 & 2 \\
\hline Dobradiça & $\mathrm{A}_{34}$ & 2252,34 & 8 & 3 & Telha Fibrocimento & $\mathrm{A}_{75}$ & 928,20 & 3 & 1 \\
\hline ESGOTO & $\mathrm{A}_{35}$ & 26485,44 & 3 & 1 & Tijolo Cerâmico 8 furos & $\mathrm{A}_{76}$ & 16378,43 & 3 & 2 \\
\hline Estronca de Madeira & $\mathrm{A}_{36}$ & 23572,04 & 7 & 3 & Tijolo $5 \times 10 \times 20 \mathrm{~cm}$ & $\mathrm{~A}_{77}$ & 3685,82 & 2 & 3 \\
\hline Extintor Pó Químico 4kg & $\mathrm{A}_{37}$ & 1680,00 & 1 & 1 & Tinta esmalte & $\mathrm{A}_{78}$ & 5163,36 & 2 & 4 \\
\hline Fechadura Completa & $\mathrm{A}_{38}$ & 20046,60 & 30 & 3 & Tinta PVA & $\mathrm{A}_{79}$ & 649,07 & 2 & 1 \\
\hline Ferragens Tapume & $\mathrm{A}_{39}$ & 1155,00 & 2 & 1 & Verniz Acrílico & $\mathrm{A}_{80}$ & 13965,01 & 15 & 1 \\
\hline Fundo branco fosco & $\mathrm{A}_{40}$ & 3395,93 & 15 & 3 & Viga Peroba de $6 \times 12 \mathrm{~cm}$ & $\mathrm{~A}_{81}$ & 864,00 & 3 & 1 \\
\hline Grade de Madeira Lei & $\mathrm{A}_{41}$ & 21672,00 & 8 & 4 & & & & & \\
\hline
\end{tabular}

